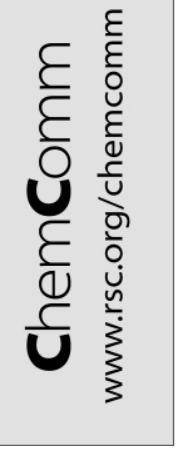

\title{
A novel supramolecular assembly in an iron(III) compound exhibiting magnetic ordering at $70 \mathrm{~K} \dagger$
}

\author{
Donatella Armentano, ${ }^{a}$ Giovanni De Munno, $* a$ Teresa F. Mastropietro, ${ }^{a}$ Miguel Julve ${ }^{* b}$ and Francesc \\ Lloret $^{b}$ \\ a Dipartimento di Chimica, Università degli Studi della Calabria, 87030 Arcavacata di Rende, Cosenza, \\ Italy.E-mail: demunno@unical.it \\ ${ }^{b}$ Departament de Química Inorgànica/Instituto de Ciencia Molecular, Faculat de Química de la Universitat \\ de València, Avda. Dr. Moliner 50, 46100 Burjassot,(València), Spain. E-mail: miguel.julve@uv.es
}

Received (in Cambridge, UK) 10th February 2004, Accepted 30th March 2004

First published as an Advance Article on the web 21st April 2004

Ethyl-substituted ammonium cation allows the preparation of an unprecedented oxo- and oxalato-bridged supramolecular three-dimensional network. The compound exhibits magnetic ordering with $T_{\mathrm{c}}=70 \mathrm{~K}$ due to a weak spin canting.

Coordination chemistry of paramagnetic metal ions exhibiting extended networks represents an important area of current research. ${ }^{1,2}$ The interest in this class of compounds is enhanced when additional properties, such as spontaneous magnetization at high temperatures, are involved. ${ }^{3}$ In this respect, over the last decade, considerable efforts have been devoted to the preparation of two- and three-dimensional oxalate-bridged bimetallic compounds, where ferro-, ferri- and antiferromagnetic long-range magnetic ordering with $T_{\mathrm{c}}$ ranging from 5 up to $44 \mathrm{~K}$ was observed. ${ }^{4}$

Very recently, we have described a three-dimensional homometallic compound of formula $\left\{\left[\mathrm{NH}_{4}\right]_{2}\left[\mathrm{Fe}_{2} \mathrm{O}(\mathrm{ox})_{2} \mathrm{Cl}_{2}\right] \cdot 2 \mathrm{H}_{2} \mathrm{O}\right\}_{n}(\mathbf{1})$ which contains isotropic high-spin $\mathrm{Fe}$ (III) ions bridged by oxo and bisbidentate oxalate groups ${ }^{5}$ and exhibits a ferromagnetic phase transition at $T_{\mathrm{c}}=40 \mathrm{~K}$. A weak spin canting, which has its origin in the antisymmetric exchange, accounts for this magnetic ordering. Aiming at investigating the role of the univalent cation on the spin canting and its influence on the $T_{\mathrm{c}}$ value, we have initiated a systematic study with a series of univalent ammonium derivatives. Our first attempts afforded the three-dimensional compound, analogous to 1, exhibiting magnetic ordering at $T_{\mathrm{c}}=56 \mathrm{~K}$ (dimethylammonium cation). ${ }^{6}$ The use of ethylammonium cation gives rise to a very singular iron(III) compound of formula $\left\{\left[\mathrm{EtNH}_{3}\right]\left[\mathrm{Fe}^{\mathrm{III}}\left(\mathrm{H}_{2} \mathrm{O}\right)_{6}\right] \mathrm{Fe}^{\mathrm{III}}\left[\mathrm{Fe}^{\mathrm{III}}{ }_{2} \mathrm{O}(\mathrm{ox})_{3} \mathrm{Cl}_{2}\right]\left[\mathrm{Fe}^{\mathrm{III}}(\mathrm{ox})_{2} \mathrm{Cl}_{2}\right]\right\}_{n^{-}}$-

$6 n \mathrm{H}_{2} \mathrm{O}(2)$, which shows a totally different three-dimensional framework from that of $\mathbf{1}$. The $T_{\mathrm{c}}$ value in $\mathbf{2}$ has been shifted to 70 $\mathrm{K}$ through spin canting. Its preparation, $\$ \mathrm{X}$-ray crystal structure $\S$ and preliminary magnetic characterization $\|[$ are reported herein.

Compound 2 consists of $\left[\mathrm{Fe}_{2} \mathrm{O}(\mathrm{ox})_{3} \mathrm{Cl}_{2}\right]^{4-}$ chains (I) and $\left[\mathrm{Fe}(\mathrm{ox})_{2} \mathrm{Cl}_{2}\right]^{3-}$ monomeric units (II) self-assembled in an unprecedented supramolecular three-dimensional anionic network through $\mathrm{Fe}^{3+}$ cations (III). The electroneutrality is achieved by means of $\left[\mathrm{Fe}\left(\mathrm{H}_{2} \mathrm{O}\right)_{6}\right]^{3+}$ (IV) and $\mathrm{EtNH}_{3}{ }^{+}$cations that are linked to the network through hydrogen bonds, in which crystallization water molecules are involved. Keeping in mind the three-dimensional network of 1 where all iron(III) ions are equivalent, being bridged by oxalato and oxo groups, the substantial difference in $\mathbf{2}$ is due to the occurrence of four different iron(III) centers, depending on their relative environments. Among these, only the metal center of type I shows the same surrounding as in $\mathbf{1}$, even if in $\mathbf{2}$ the overall motif is a chain containing iron(III) atoms with regular alternation of oxo and oxalate bridges. No significant variations have been observed in the $\mathrm{Fe}-\mathrm{O}_{\text {ox }}$ and $\mathrm{Fe}-\mathrm{O}_{\text {oxo }}$ bond lengths [range 2.006(8)-2.109(8) and 1.931(9) $\AA$ average value, respectively] with respect to

$\dagger$ Electronic supplementary information (ESI) available: Thermal dependence of $\chi_{\mathrm{M}} \mathrm{T}$ under an applied field of $50 \mathrm{Oe}$ and of the in-phase and outphase components of the ac susceptibility of 2 at $100 \mathrm{~Hz}$ in zero applied static field and under an oscillating field of $1 \mathrm{Oe}$ (Fig. S1 and S2); hysteresis loop at $2.0 \mathrm{~K}$ between $\pm 5 \mathrm{~T}$ (Fig. S3). See http://www.rsc.org/suppdata/cc/ $\mathrm{b} 4 / \mathrm{b} 402055 \mathrm{c} /$ compound 1 [2.049(4)-2.194(4) and 1.825(2) $]$. The value of the angle at the oxo bridge is $134.8(5)^{\circ},\left[135.9(4)^{\circ}\right.$ in 1$]$ the smallest one reported so far for oxo-bridged iron(III) compounds [the previous values ranging from $139^{\circ}$ to $\left.180^{\circ}\right] .5^{\circ}$ The values of the $\mathrm{Fe} \cdot \mathrm{F}$ Fe distances through the oxo and oxalate bridges are 3.565(2) and 5.421(2) $\AA$, respectively [3.384(2) and 5.496(2) $\AA$ in 1]. The $\left[\mathrm{Fe}(\mathrm{ox})_{2} \mathrm{Cl}_{2}\right]^{3-}$ monomeric units II contain iron(III) ions in a distorted octahedral arrangement. The values of the $\mathrm{Fe}-\mathrm{O}_{\text {ox }}$ and $\mathrm{Fe}-$ $\mathrm{Cl}$ bond lengths are in agreement with those reported in the literature for other similar iron(III) oxalate compounds containing coordinated chloride atoms. ${ }^{5-7}$

$\mathrm{Fe}$ (III) cations (III) are weakly coordinated to eight oxygen atoms of four oxalate groups, which interact with the chains $\mathbf{I}$ and the monomeric units II to form a supramolecular assembly. As far as we know, this is the third example of a compound containing an eight-coordinated iron(III) to be authenticated by X-ray studies. ${ }^{8}$ The $\mathrm{Fe} \cdots \mathrm{O}_{\mathrm{ox}}$ bond distances [ranging from 2.40(1) to 2.50(1) $\AA$ ], are longer that those reported for the other two similar compounds [2.13(3) $\AA$ and 2.211(3)-2.325(3) $\AA$ ]. This lengthening could suggest that the $\mathrm{Fe}(\mathrm{III})$ ions (III) in $\mathbf{2}$ are involved in weaker interactions with respect to the other octa-coordinated iron(III) complexes. The resulting supramolecular structure (Fig. 1) is noteworthy. A pair of $\left[\mathrm{Fe}(\mathrm{ox})_{2} \mathrm{Cl}_{2}\right]^{3-}$ monomeric units (II) is linked to two $\mathrm{Fe}^{\mathrm{III}}$ ions (III) building a ring in the $a c$ plane. The chains $\mathbf{I}$ are linked to the rings through supramolecular interactions with $\mathrm{Fe}$ III ions (III). The $\left[\mathrm{Fe}\left(\mathrm{H}_{2} \mathrm{O}\right)_{6}\right]^{3+}$ cations (IV) (Fig. 2) occupy the central part of the ring holes and are linked to the rings by means of hydrogen bonds. As far as we know, this is the second example of a crystal structure showing these $\left[\mathrm{Fe}\left(\mathrm{H}_{2} \mathrm{O}\right)_{6}\right]^{3+}$ moieties, ${ }^{9}$ and again their occurrence is observed in an oxo-bridged iron(III) complex.

The magnetic behaviour of $\mathbf{2}$ is typical of a spin canted system. $\chi_{\mathrm{M}} T$ for $2\left[\chi_{\mathrm{M}}\right.$ is the magnetic susceptibility per one iron(III) ion] at room temperature is $1.83 \mathrm{~cm}^{3} \mathrm{~mol}^{-1} \mathrm{~K}$, below that calculated for a

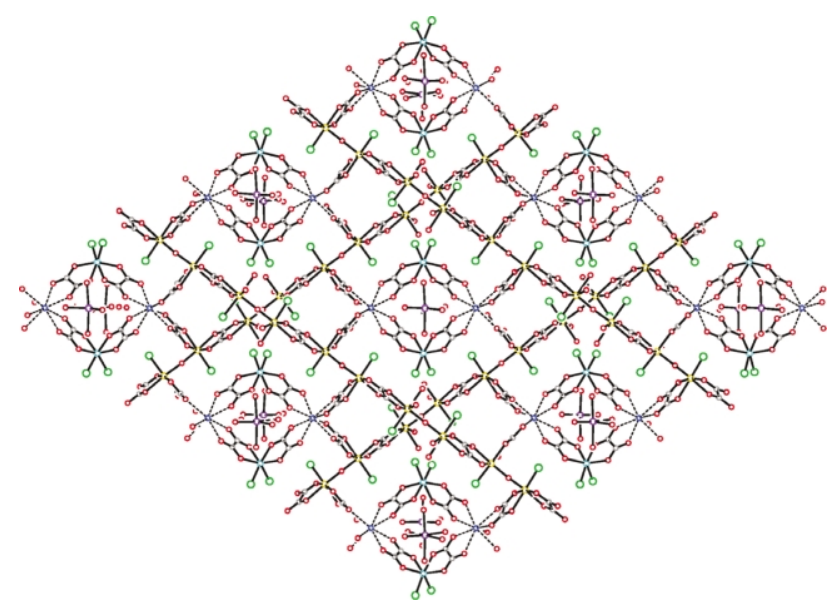

Fig. 1 View along $b$ axis of the three-dimensional supramolecular network of $\mathbf{2}$ showing the different types of iron(III) ions. Eight-coordinated iron(III) interactions are represented by dashed lines. 
magnetically isolated $\mathrm{S}_{\mathrm{Fe}(\mathrm{III})}=5 / 2\left(4.38 \mathrm{~cm}^{3} \mathrm{~mol}^{-1} \mathrm{~K}\right.$ with $g=$ 2.0) indicating that a strong antiferromagnetic interaction occurs in agreement with the presence of oxo $(-J$ values larger than 45 $\left.\mathrm{cm}^{-1}, H=-J S_{\mathrm{A}} \cdot S_{\mathrm{B}}\right)$ and oxalate $\left(-J\right.$ values about $\left.7 \mathrm{~cm}^{-1}\right)$ bridges. ${ }^{6}$ Upon cooling under an applied magnetic field of 50 Oe [Fig. $\mathrm{S} 1 \dagger], \chi_{\mathrm{M}} T$ decreases, attains a minimum at $73 \mathrm{~K}\left(\chi_{\mathrm{M}} T=0.62\right.$ $\mathrm{cm}^{3} \mathrm{~mol}^{-1} \mathrm{~K}$ ), then exhibits an abrupt increase and further decreases in the very low temperature range. At $T<73 \mathrm{~K}$, the magnetization of $\mathbf{2}$ is strongly field dependent and the field-cooled magnetization of 2 (Fig. 3) at $50 \mathrm{G}$ reveals the occurrence of magnetic ordering below $70 \mathrm{~K}$.

In-phase and out-of phase ac signals, which are frequency independent (frequency range 1000-10 Hz), are observed below 70 $\mathrm{K}$ [Fig. S $†$; , confirming the magnetic ordering. The magnetic hysteresis loop for $\mathbf{2}$ (see inset of Fig. 1 and Fig. S3 $\dagger$ ) shows values of the coercive field $\left(H_{\mathrm{c}}\right)$ and remnant magnetization $\left(M_{\mathrm{r}}\right)$ of 0.06 $\mathrm{T}$ and $0.020 \mathrm{BM}$. Although no saturation of the magnetization for

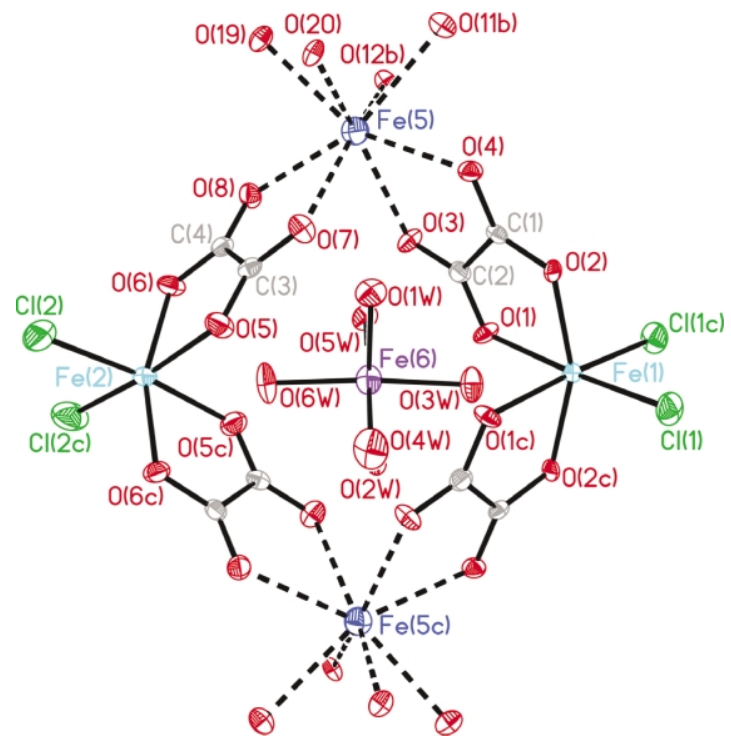

Fig. 2 View of the ring motif of 2 containing six- and eight-coordinated iron(III) atoms. Eight-coordinated iron(III) interactions are represented by dashed lines. Selected bond lengths [̊]: $\mathrm{Fe}(5)-\mathrm{O}(3) 2.426(9), \mathrm{Fe}(5)-\mathrm{O}(4)$ 2.473(10), $\mathrm{Fe}(5)-\mathrm{O}(7)$ 2.406(10), $\mathrm{Fe}(5)-\mathrm{O}(8)$ 2.502(10), $\mathrm{Fe}(5)-\mathrm{O}(11 \mathrm{~b})$ 2.443(10), Fe(5)-O(12b) 2.479(9), Fe(5)-O(19) 2.447(11), Fe(5)-O(20) 2.448(9). Symmetry code: (b) $0.5-x,-y, 0.5+z$.

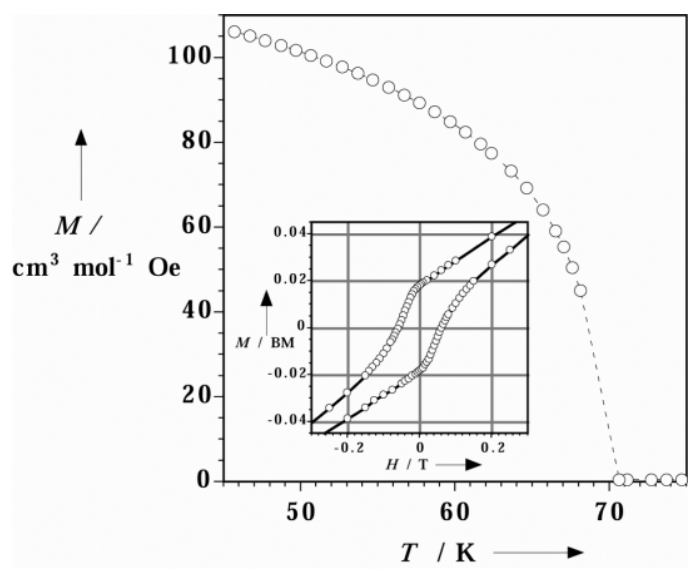

Fig. 3 Field-cooled magnetization $(\bigcirc)$ of $\mathbf{2}$ under an external field of 50 Oe. The inset shows the hysteresis loop of 2 at $2.0 \mathrm{~K}$ between $\pm 0.30 \mathrm{~T}$. The dashed line is an eye guide. the spin canting occurs, a lower limit of the value of the spin canting of $0.5^{\circ}$ can be estimated from the expected saturation value of the magnetization for a spin $\mathrm{S}=5 / 2(5 \mathrm{BM})$ and considering the value of $M_{\mathrm{r}}(0.020 \mathrm{BM})$ as that of the saturation value of the magnetization of 2 . From the two mechanisms that lead to spin canting, namely the magnetic anisotropy and the antisymmetric exchange, the second one has to be responsible for the canting in $\mathbf{2}$, because of the isotropic character of the high spin iron(III). The acentric character of the space group of $\mathbf{2}$ is compatible with the occurrence of the antisymmetric exchange. ${ }^{10}$ The relative high value of $T_{\mathrm{c}}$ for 2 and its significant shift of $30 \mathrm{~K}$ towards higher temperatures when comparing $\mathbf{1}$ and $\mathbf{2}$ is very appealing.

The greater number of correlations paths (number of connections between the iron atoms) in $\mathbf{2}$ when compared to $\mathbf{1}$, which is due to the presence of eight-coordinated iron(III), is most likely at the origin of the significant increase of $T_{\mathrm{c}}$ in $\mathbf{2}$. In $\mathbf{1}$, each iron atom is six-coordinated and it is linked to only three nearest-neighbours. Additional work is in progress on these spin canted threedimensional systems in order to get further insights on the correlation between the network topology and the $T_{\mathrm{c}}$ value.

This research was supported by the Italian Ministero dell'Università e della Ricerca Scientifica e Tecnologica, the Ministerio Español de Ciencia y Tecnología (Project BQU2001-2928) and the Agencia Valenciana de Ciencia y Tecnología (Grupos 03/197).

\section{Notes and references}

† Compound 2 was obtained (yield about 60\%), as yellow rhomboid crystals, by slow evaporation of an aqueous solution (total volume $10 \mathrm{ml}$ ) containing $\mathrm{FeCl}_{3}, \mathrm{H}_{2} \mathrm{Ox}$ and $\mathrm{EtNH}_{3} \mathrm{Cl}$ in the 1:1:1 molar ratio $(2 \mathrm{mmol})$. Anal. Calcd for $\mathrm{C}_{12} \mathrm{H}_{32} \mathrm{Cl}_{4} \mathrm{Fe}_{5} \mathrm{NO}_{33}: \mathrm{C} 12.65, \mathrm{H} 2.83, \mathrm{Cl} 12.45, \mathrm{~N} 1.23$. Found: C 12.60, H 2.75, Cl 12.50, N 1.31\%. IR data for $2\left[\mathrm{v} / \mathrm{cm}^{-1}\right]$ on $\mathrm{KBr}$ pellets: 1675 vs $v_{\text {as }}(\mathrm{O}-\mathrm{C}-\mathrm{O}) ; 1355 \mathrm{~m}$ and $1305 \mathrm{~s} v_{\mathrm{s}}(\mathrm{O}-\mathrm{C}-\mathrm{O}) ; 805 \mathrm{~m} \delta(\mathrm{O}-\mathrm{C}-$ O); $825 \mathrm{~m} v_{\text {as }}(\mathrm{Fe}-\mathrm{O}-\mathrm{Fe}) ; 3588 \mathrm{~s}$, br $\left(\mathrm{H}_{2} \mathrm{O}\right)$.

$\S$ Crystal data of compound 2: $\mathrm{C}_{12} \mathrm{H}_{32} \mathrm{Cl}_{4} \mathrm{Fe}_{5} \mathrm{NO}_{33}, M_{\mathrm{r}}=1139.44$, orthorhombic, space group $F d d 2$ (refinement in $F d d d$ was unsuccessful), $a=27.328(6), b=32.125(6), c=18.424(4) \AA, V=16175(6) \AA^{3}, Z=16$, $\rho_{\text {calcd }}=1.872 \mathrm{~g} \mathrm{~cm}^{-3}, \lambda=0.71073 \AA, \mu\left(\mathrm{Mo}_{\mathrm{K} \alpha}\right)=21.18 \mathrm{~cm}^{-1}, F(000)=$ $9168, \mathrm{GoF}=1.083$. A total of 3787 reflections were collected and 3704 were unique. $R 1$ and $w R 2$ were 0.0663 and 0.205 respectively, for 497 parameters and 3258 reflections $[I>2 \sigma(I)]$. The hydrogen atoms of the water molecules were not located. CCDC 221514. See http://www.rsc.org/ suppdata/cc/b4/b402055c/ for crystallographic data in .cif or other electronic format.

II Magnetic measurements were carried out on a polycrystalline sample (10 $\mathrm{mg}$ ) of 2 in the temperature range 1.9-295 K with a Quantum Design SQUID susceptometer and using applied magnetic field ranging from $50 \mathrm{G}$ to $5 \mathrm{~T}$. The susceptibility data of $\mathbf{2}$ were corrected for the diamagnetic contributions of the constituent atoms and sample holder.

1 Molecule Based Materials, (eds.) J. S. Miller and M. Drillon, WileyVCH, Weinheim, 2001.

2 P. Day, J. Chem. Soc., Dalton Trans., 2000, 3483.

3 O. Kahn, Adv. Inorg. Chem., 1995, 43, 179.

4 M. Pilkington and S. Decurtins, Comprehensive Coordination Chemistry II. From Biology to Nanotechnology, (eds.) J. A. McCleverty and T. J. Meyer, 2004 Vol. 7, Elsevier, Amsterdam, pp. 177 and references therein.

5 D. Armentano, G. De Munno, F. Lloret, A. V. Palii and M. Julve, Inorg. Chem., 2002, 41, 2007.

6 D. Armentano, G. De Munno, T. F. Mastropietro, D. M. Proserpio, M. Julve and F. Lloret, work in progress.

7 M. Feist, S. Troyanov and E. Kemnitz, Inorg. Chem., 1996, 35, 3067.

8 (a) T. J. King, N. Logan, A. Morris and S. C. Wallwork, Chem. Commun., 1971, 554; (b) W. O. Koch, A. Barbieri, M. Grodzicki, V. Schünemann, A. X. Trautwein and H.-J. Kruger, Angew. Chem. Int. Ed., 1996, 35, 422.

9 P. J. Junk, B. J. McCool, B. Moubaraki, K. S. Murray, L. Spiccia, J. D. Cashion and J. W. Steed, Dalton Trans., 2002, 1024.

10 (a) I. Dzyaloshinsky, J. Phys. Solids, 1958, 4, 241; (b) T. Moriya, Phys. Rev., 1960, 120, 91. 